\title{
Relação de Trabalho x Relação de Consumo: Uma Análise Sobre a Limitação da Competência da Justiça do Trabalho
}

\section{Saulo Nunes de Carvalho Al meida}

Bacharel em Direito pela Universidade de Fortaleza (Unifor). Pós-graduando em Direito do Trabalho, Tributário e Previdenciário pela Faculdade Ateneu. saulonunes@hotmail.com

\section{Antonia Morgana Coel ho Ferreira}

Bacharela em Direito pela Universidade de Fortaleza (Unifor). Pós-graduanda em Direito e Processo do Trabalho pelo Curso Prof. Jorge Hélio. Advogada. morganacferreira@hotmail.com

Sumário: Introdução. 1. Novas competências da Justiça do Trabalho. 2. Relações de consumo x relações de trabalho. 3. O atual entendimento do TST. Conclusão. Referências.

Resumo: O presente estudo mostra qual a justiça competente para se analisar relações de consumo e relações de trabalho, introduzindo formas para que seja realizada uma diferenciação entre ambas. Para alcançar tal objetivo, esclarece-se o que são tais relações, analisando-se cuidadosamente a competência da Justiça do Trabalho que, desde a Emenda Constitucional n ${ }^{\circ} 45$, ainda provoca controvérsias entre os estudiosos do assunto. Analisa-se, outrossim, a questão de conflito de competências entre a justiça responsável por analisar relações de prestação de serviços, entendidas como eminentemente civis, trazendo à discussão o entendimento atual dos tribunais sobre essas questões e as correntes doutrinárias defendendo diferentes posições e o entendimento dominante na doutrina.

Palavras-chave: Competência. Relações de trabalho e consumo. Emenda constitucional $n^{\circ} 45$. 


\section{INTRODUÇÃO}

Sabe-se que, a partir da publicação da Emenda Constitucional 45, tem-se oportunamente questionado até que ponto a Justiça do Trabalho teve suas competências alargadas pelo novo teor do artigo 114, da Lei Maior.

Inicialmente, para que se possa almejar a necessária compreensão quanto à matéria aqui defendida, é de vital importância a inexistência de dúvida quanto à limitação da matéria a ser estudada. Ao se falar de competência, fala-se sobre um gênero que, em regra, forma-se por quatro ramos fundamentais, que são: competência material (ex ratione materiae), competência pessoal (ex ratione personae), competência territorial (ex ratione loci) e competência funcional (atribuições).

Pois bem, o presente estudo analisará a nova competência material da Justiça do Trabalho. Porém, é importante destacar que não se tem aqui a pretensão de esgotar as questões temáticas, referentes à relação de trabalho e relação de consumo, aqui abordadas. Pelo contrário, o verdadeiro intuito é o de colaborar com aqueles que têm se debruçado sobre este instigante tema.

Portanto, será defendido neste estudo que, apesar de uma análise à primeira vista da expressão "relação de trabalho" e o que por ela pode ser englobado, bem como a tentação da generalização de que seja abrangido toda forma de prestação de serviço, não se deve cometer o equívoco de confundir relação de consumo com relação de trabalho, onde os primeiros aparentam escapar do gênero relação de trabalho e, por consequência, devem ser excluídos da competência ${ }^{2}$ dada à Justiça do Trabalho pela Reforma do Judiciário.

\section{NOVAS COMPETÊNCIAS DAJUSTIÇA DO TRABALHO}

Ao se analisar a competência da Justiça do Trabalho por um prisma histórico, deve-se remeter ao artigo 122 da Constituição Federal de 1934, que, apesar de não utilizar expressamente a palavra "competência", afirmava que ficava instituída a Justiça do Trabalho para dirimir questões envolvendo empregados e empregadores, criando assim, tacitamente, a competência da Justiça Laboral.

A significativa ampliação dessa justiça especializada ocorre no ano de 2004, após doze anos de tramitação do Projeto de Emenda Constitucional nº 45/2004, que no dia 31/12/2004 ensejou na publicação da Emenda Constitucional nº 45. Essa emenda trouxe nova redação ao art. 114 da atual Constituição Federal,

\footnotetext{
l Relação de trabalho é gênero do qual relação de emprego é espécie.

2 Palavra que vem do latim competentia, que significa estar no gozo ou ser capaz.
} 
ampliando a competência material da Justiça do Trabalho, para analisar não apenas as relações entre "trabalhadores e empregadores", e, sim, para todas as lides oriundas da "relação de trabalho."

Porém, muitas são as dúvidas que têm surgido entre os doutrinadores quanto a essa nova competência material da Justiça Laboral, ramo do direito que mais foi modificado pelas inovações introduzidas pela $\mathrm{EG} \mathrm{n}^{\circ} 45$, de 31.12.2004. Entre os distintos entendimentos que são defendidos pelos estudiosos atualmente, três são as correntes que mais se sobressaem.

Inicia-se pela corrente que, até o presente momento, aparenta estar se desenhando como a majoritária perante a doutrina nacional, que tem sido chamada de corrente ampliativa. Essa corrente defende o entendimento quanto à competência da Justiça do Trabalho em qualquer relação em que exista uma prestação de atividade humana, incluindo-se aqui qualquer forma de relação de trabalho, bem como a controversa relação de consumo.

Ao defender essa corrente, que entende que a partir da Emenda Constitucional $n^{\circ} 45$ a Justiça do Trabalho passou a ter competência para julgar as ações oriundas da relação de consumo, Rodolfo Pamplona Filho (2006, p. 42) traz uma interpretação histórica do polêmico artigo Constitucional:

Em outras palavras, mantendo a coerência histórica na interpretação da evolução constitucional da competência trabalhista, envolvendo a lide sujeitos que estejam na qualificação jurídica de trabalhadores e tomadores desse serviço, a competência será da Justiça do Trabalho.

$[\ldots]$

Agora, todas as ações oriundas da relação de trabalho (para muitos, relação de emprego), no que não temos como desprezar os contratos civis, consumeristas ou outros contratos de atividade (quando se referirem à discussão sobre a valorização do trabalho humano), deverão ser ajuizadas, a partir da Reforma do Judiciário, na Justiça do Trabalho.

Entendimento similar também é seguido por Mauro Schiavi (2009, p. 175), que afirma:

Para nós a razão está com a vertente interpretativa no sentido de que tanto as ações propostas pelo prestador de serviços no mercado de consumo, quanto as ações em face deles propostas pelos consumidores tomadores, são da competência da Justiça do Trabalho.

A segunda corrente, minoritária entre os entendimentos dos doutrinadores e dos Tribunais especializados, adota uma postura restritiva quanto à interpretação do novo texto do art. 114 da CF, não aceitando a expressão "relação de trabalho" trazida no texto da lei, desconsiderando a amplitude dada à Justiça do Trabalho e defendendo a sua competência apenas para os conflitos decorrentes da relação de emprego. Ou seja, 
entendem que onde a lei traz "relação de trabalho" deve-se entender como "relação de emprego", não tendo a competência material da Justiça do Trabalho sido ampliada pela EC n ${ }^{\circ} 45$.

A terceira e última corrente, que até o momento aparenta ser a mais correta, tem sido denominada de corrente intermediária. Essa corrente, defendida por doutrinadores como Carlos Henrique Bezerra Leite, faz uma interpretação literal do mencionado artigo da Carta Magna, defendendo a ampliação quanto à competência material da Justiça do Trabalho para processar qualquer atividade de trabalho humano, conforme a inteligência do art. 114 da CF.

Inegável o fato de que a ideia do novo texto do mencionado artigo constitucional é a de que qualquer matéria envolvendo relação de trabalho passe a ser processada na Justiça do Trabalho, e não apenas as que se originam de uma relação de emprego.

Porém, torna-se claro que, devido ao conceito de Justiça do Trabalho como uma justiça especializada (bem como a Justiça Militar ou Eleitoral) para resolver as lides trabalhistas, não se pode realizar uma interpretação ampliativa do supracitado dispositivo, incluindo as relações de consumo.

No entanto, maiores considerações quanto à defesa dessa corrente ocorrerão em momento oportuno ${ }^{3}$, que distinguirá relação de consumo de relação de trabalho, porém, adianta-se desde já o empecilho da relação de consumo ser regida por lei distinta da relação de trabalho, seja pelo Código Civil ou pelo Código de Defesa do Consumidor, bem como lhe serem aplicados princípios distintos daqueles de uma relação de trabalho.

Dessa forma, deve-se entender que a relação de consumo não foi englobada pela nova competência da Justiça do Trabalho, pois entendimento contrário poderá levar a um desvirtuamento do sentido de atuação dessa Justiça especializada. Ao dissertar sobre a questão, Sergio Pinto Martins (2006, p. 106) afirma:

\footnotetext{
Lide entre consumidor e prestador de serviços, em que irá ser aplicado o Código do Consumidor, não é de competência da Justiça do Trabalho, por se tratar de relação de consumo, que têm natureza econômica. Exemplos são a relação do paciente com o médico em decorrência da operação malfeita, do cliente contra outra pessoa física que faz conserto incorreto de um aparelho eletrônico. São hipóteses que envolvem relação de consumo e não exatamente de trabalho.
}

Importante destacar nesse ponto que, independentemente de se adotar a corrente ampliativa ou a literal, a competência material, que aqui se discute, referente à relação de consumo, limita-se às relações as quais o prestador de serviços é pessoa física, afinal,

\footnotetext{
3 Ver capítulo Relação de Consumo x Relação de Emprego..
} 
se o mesmo fosse uma pessoa jurídica, como por exemplo um escritório de advocacia, jamais existiria a possibilidade de uma relação de trabalho, pela óbvia impossibilidade de se estabelecer o intuitu personae.

O real intuito da reforma constitucional trazida pela $\mathrm{EG}^{\circ} 45$ aparenta ser o de proteção ao trabalhador, retirando do campo da "informalidade" diversas atividades laborais, como os trabalhadores autônomos, eventuais, cooperados, temporários, entre outros, atuando de forma a combater a constante presença de fraudes ligadas a essas formas de contrato. Não parece ser correta a assertiva de que o intuito da reforma era o de também alcançar a relação de consumo, retirando-lhe da competência da Justiça Comum e inserindo na Justiça do Trabalho. Afinal, relação de trabalho é um gênero, do qual relação de consumo nele não se insere como possível espécie.

\section{RELAÇÕES DE CONSUMO X RELAÇÕES DE TRABALHO}

Sabe-se que, historicamente, a legislação trabalhista surge da crescente necessidade de se estabelecerem certos limites à exploração da força de trabalho por parte do empregador, que por possuir os mecanismos de produção tinha o controle dessa relação, utilizando de forma abusiva a mão de obra prestada pela parte hipossuficiente, em uma constante busca por maiores lucros.

Porém, essa supramencionada realidade não é, e jamais foi, a realidade encontrada em uma relação de consumo. Muito pelo contrário, via de regra, nesse caso, o prestador de serviços possui mais força que o polo receptor (consumidor).

Assim, não parece razoável o sentido histórico alcançado com a criação desta justiça especializada quando da defesa de uma inserção das relações de consumo na competência da Justiça do Trabalho.

Porém, por maior que seja a tentação quanto à defesa da incompetência da Justiça do Trabalho para tratar de lides oriundas da relação de consumo, a verdade é que inexiste a possibilidade de uma classificação absoluta e imutável quanto à defesa da relação de consumo ser englobada pela Justiça Comum, pois existe a possibilidade de uma mesma situação, de fato, dependendo das circunstâncias que lhe cercam, ser competência de Justiça distintas.

Para ilustrar a afirmação, imagine-se a seguinte relação: uma pessoa comparece a uma clínica particular para realizar uma cirurgia de estética por um médico autônomo que presta serviços na mencionada clínica. Em tal caso concreto existirão duas distintas relações com duas distintas competências. Caso o cliente que compareceu à clínica não tenha ficado satisfeito com o procedimento cirúrgico realizado e almeje uma possível reparação, configura-se uma relação de consumo, que foge à competência da Justiça do Trabalho, devendo seu pleito ser apresentado perante a Justiça Comum Estadual, tratando-se de clara situação regida por lei especial. Porém, já no caso do médico 
não ter recebido os honorários que lhe eram devidos pela mencionada clínica, deverá ajuizar reclamação perante a Justiça do Trabalho, competente para julgar a presente demanda, por tratar-se de relação de trabalho.

Portanto, para uma mesma relação podem-se ter distintas competências, a depender de cada caso concreto. Concordando com a situação acima esposada, destaca-se o entendimento de Wagner D. Giglio e Claudia Giglio Veltri Corrêa (2005, p. 44) que trazem didático entendimento sobre o assunto:

A transferência de um bem móvel, de uma para outra pessoa, pode ser qualificada, juridicamente, de contrato de compra e venda, de leasing, de empréstimo, de consignação ou de furto, dependendo das circunstâncias e da intenção do agente.

Assim, o que se deve procurar na verdade não é o "rótulo" ao qual se encontra atrelada a relação concreta, e, sim, uma aplicação efetiva da primazia da realidade. Afinal, são relativos os elementos que deverão ser examinados em cada caso concreto.

Porém, configurando-se uma verdadeira relação de consumo no caso concreto, a competência material para processar e julgar a lide será da justiça comum, aplicandose a lei especial (CDC) ou o próprio Código Civil. Afinal, tratando-se de uma prestação de serviço originada pela celebração de contrato de natureza eminentemente civil, não se pode argumentar quanto à competência da Justiça do Trabalho. Assim, é o teor do art. 593, do CG: "A prestação de serviço que não estiver sujeita às leis trabalhistas ou a lei especial, reger-se-á pelas disposições deste Capítulo."

Em palestra proferida, a ministra do Tribunal Superior do Trabalho, Maria Cristina Irigoyen Peduzzi ${ }^{4}$, ao analisar o intuito do legislador em alargar a competência material da Justiça do Trabalho, afirma:

Fica clara a preocupação do legislador com o acesso efetivo à Justiça. Já vimos que à garantia de acesso apenas formal à Justiça, desde o início do século XX, foi acrescida a preocupação com o acesso efetivo. De nada adianta poder ir ao juízo e ter uma resposta, se ela não vem em tempo hábil e nem é capaz de realizar os objetivos da jurisdição. Há obstáculos que devem ser rompidos, e um deles é o da demora na prestação jurisdicional.

A verdade é que o acesso do necessitado ao Poder Judiciário Trabalhista é, e sempre foi, significativamente mais célere do que nos demais órgãos do Poder Judiciário. Assim, torna-se preocupante um equivocado entendimento que acarrete em uma ampliação além da vontade do legislador, podendo vir a refletir diretamente na efetividade de seu

${ }^{4}$ Publicado na Revista Trabalho e Ambiente, 2006, n. 6. 
funcionamento, sofrendo um significativo aumento no número de demandas a serem analisadas, tendo como consequência natural uma maior morosidade, levando, certamente, à diminuição do acesso à Jurisdição por parte da população.

É inegável, apesar do que afirma a mencionada corrente restritiva, que a Emenda Constitucional $n^{\circ} 45$ ampliou significativamente a competência da Justiça do Trabalho. Porém, resta claro também que essa Justiça especializada é incompetente para avaliar lides que se originam da relação de consumo, pelo óbvio motivo de não se tratar de uma relação de trabalho.

\section{AT UAL ENTENDIMENTO DO TST}

O Tribunal Superior do Trabalho tem tido um entendimento cauteloso ao tratar dessa delicada questão de inserção das relações de consumo na competência material da Justiça do Trabalho. Seguindo o seu conservadorismo costumeiro, tem-se preferido a não absorção de tais relações como matéria a ser dirimida por essa justiça especializada, apesar das inegáveis características existentes entre relação de trabalho e relação de consumo, que, de fato, guardam diversas semelhanças.

Daí advém a importância, já ressaltada previamente, de uma minuciosa análise do caso concreto, seguindo o espírito da primazia da realidade, ao avaliar se o contrato que, à primeira vista aparenta tratar de uma relação de consumo, não é, na verdade, uma fraude escondendo uma real relação de trabalho.

Portanto, a defesa que aqui se faz de uma ausência de competência da Justiça do Trabalho para tratar de questões de consumo jamais poderá conduzir o entendimento do intérprete ao absurdo de considerar essa regra sem exceção, devendo-se sempre buscar uma interpretação sistemática do caso concreto que se apresenta, na procura de descobrir se pode ou não ser ele incluído na "relação de trabalho" de que trata o art. 114 da CF/88.

O ministro Lélio Bente Corrêa, atuando como relator de um recurso de revista que defendia a competência da Justiça do Trabalho para dirimir questões referentes a contratos de prestação de serviços, adotou a corrente literal, ou intermediária, ao defender a visão de que por ser o objeto decorrente de um contrato de resultado, onde o trabalho não mais aparenta ser o cerne do contrato, mas sim um bem de consumo, que é o resultado esperado por parte de quem contrata, faz com que a natureza dessa relação encontre-se fora da competência material da Justiça do Trabalho.

Pelo seu teor didático, e por trazer um rol exemplificativo de funções, relevantes nesse momento, transcreve-se a ementa ${ }^{5}$ :

\footnotetext{
${ }^{5}$ Tem sido farta a jurisprudência do TST seguindo o mesmo entendimento.
} 
INCOMPETÊNCIA DA JUSTIÇA DO TRABALHO. GOBRANÇA DE HONORÁRIOS PROFISSIONAIS. CONTRATO DE PRESTAÇÃ̃O DE SERVIÇOS. Não se insere na competência da Justiça do Trabalho a tarefa de dirimir controvérsia relativa à prestação dos serviços levada a cabo por profissional autônomo que, senhor dos meios e das condições da prestação contratada, coloca-se em patamar de igualdade (senão de vantagem) em relação àquele que o contrata. Tal é o caso típico dos profissionais da engenharia, advocacia, arquitetura e medicina que exercem seus misteres de forma autônoma, mediante utilização de meios próprios e em seu próprio favor. Recurso de revista não provido (TST-RR-1.110/2007-075-02-00, Ac. $1^{a}$ Turma, Rel. Min. Lélio Bentes Corrêa, DJ 5/6/2009.)

Portanto, veja que o entendimento atual do TST vai de encontro a já mencionada doutrina majoritária, ao defender a tese de que por haver uma relação de igualdade entre as partes, senão de superioridade por parte daquele que presta o serviço, não será inserida na competência da Justiça do Trabalho, responsável por dirimir as divergências entre empregador e trabalhador, onde o segundo é hierarquicamente inferior ao primeiro, hipossuficiente portanto. Diferente é o caso do prestador de serviços, esse ocupa posto de igualdade (ou até superioridade) em relação àquele que recebe seus serviços.

No entanto, cumpre ressaltar que a visão aqui destacada, apesar de majoritária, ainda não se encontra pacificada no Tribunal Superior do Trabalho, onde alguns ministros consideram como correta a interpretação ampliativa do art. 114, I, da Constituição Federal. Essa é a opinião, por exemplo, da ministra Maria de Assis Calsing, que, em relatório proferido, adota tese diametralmente oposta, no sentido de ser a Justiça do Trabalho órgão competente para julgar as lides oriundas da relação de consumo:

Embora muitas correntes tenham surgido acerca da extensão da expressão "relação de
trabalho" prevista no artigo 114, I, da Constituição Federal, filio-me à qual entende
pelo sentido mais amplo da expressão "relação de trabalho", nela incluindo não só a
relação de emprego, por óbvio, mas também toda relação que envolva prestação pessoal
de trabalho ou serviço, seja tal relação prevista na legislação civil, seja na legislação
consumerista, seja em legislação esparsa envolvendo contratos de atividade. [...]
Portanto, desde que a relação havida entre as parte, seja de que caráter for, envolver
o trabalho humano pessoal que mereça tutela, a competência será da Justiça do
Trabalho. (Proc. No TST-RR-488/2008-068-03-00.9).

O TST já foi, também, chamado a se manifestar algumas vezes quanto à questão dos honorários de advogado ${ }^{6}$ e a competência da Justiça do Trabalho para julgar essa forma de demanda de caráter consumerista, tendo seguido o entendimento de que, por se

${ }^{6}$ Honorário tem o significado de prêmio, advém da palavra latina honoratius, pois na época de Roma o cliente ao sair vencedor de uma causa prestava honrarias a seu advogado. 
tratar de uma relação de caráter estritamente civil, esse contrato de prestação de serviços será da competência da Justiça Estadual e não da Justiça do Trabalho. Destaca-se, assim, um dos diversos precedentes encontrados na Jurisprudência dessa Corte:

\begin{abstract}
AGRAVO DE INSTRUMENTO. AÇÃO DE COBRANÇA DE HONORÁRIOS ADVOGATÍCIOS. INCOMPETÊNCIA DA JUSTIÇA DO TRABALHO.

Não merece reforma o r. despacho agravado, uma vez que, analisando de forma pormenorizada todas as questões articuladas no Recurso de Revista denegado, acabou por refletir as diretrizes jurisprudenciais que têm prevalecido no âmbito desta Corte em relação ao tema ali abordado, precisamente quanto à incompetência dessa Justiça Especializada para julgar ação de cobrança de honorários advocatícios. Agravo de Instrumento não provido. (TST-AIRR-67/2007-381-04-40, Ac. $2^{\text {a }}$ Turma, Rel. Min. José Simpliciano Fontes de F. Fernandes, DJ 31/07/2009).
\end{abstract}

Em tais casos, o entendimento que tem sido aplicado é o de Gustavo Amarante Merçon $^{7}$, de que os serviços prestados pela pessoa física do advogado em favor de pessoa jurídica ou profissional liberal, que atue no âmbito de sua atividade produtiva, bem como de qualquer ente que produza bens ou serviços para o mercado, a relação será trabalhista, nos demais casos será relação de consumo.

Portanto, torna-se notória a intenção do TST em tentar sanar a atual divergência originada pela ampliação da competência da Justiça do Trabalho, delimitando essa nova competência através da adoção da corrente intermediária como forma de interpretação, defendendo o entendimento de que, ao contrário de uma relação de trabalho, em uma relação de serviços o prestador é quem explora uma necessidade do consumidor, havendo uma clara inversão quanto ao polo hipossuficiente da lide.

\title{
CONCLUSÃO
}

É evidente que, quando uma relação de consumo sai da sua esfera corriqueira de admissão de bens, e adentra esfera atípica de prestação de serviços, haverá divergências pelos intérpretes, podendo ser confundida com alguma das espécies do gênero relação de trabalho. Porém, apesar do devido respeito que merece opinião contrária, com ela não se confunde, sendo, inclusive, ideologicamente incompatível com o processo trabalhista que visa à proteção do trabalhador (parte hipossuficiente) diferentemente de toda a inteligência que traz o texto do Código de Defesa do Consumidor, favorecedor do receptor dos serviços prestados.

\footnotetext{
${ }^{7}$ LTr, vol. 05, maio/2006.
} 
Seguindo esse entendimento, o Superior Tribunal de Justiça (órgão constitucionalmente competente para julgar conflitos de competência) já se manifestou, através da Súmula $\mathrm{n}^{\circ} 363$, quanto à competência da Justiça Estadual para julgar ações de cobrança oriundas da relação entre profissional liberal e cliente: "Compete à Justiça estadual processar e julgar a ação de cobrança ajuizada por profissional liberal contra cliente.”

Quanto à mencionada "área cinzenta" de casos que transitam entre a relação de consumo e relação de trabalho, como é o caso dos profissionais liberais já exaustivamente mencionados, a solução para uma correta identificação quanto à espécie aparenta estar no fato de que, em uma relação de consumo a prestação de serviços extingue-se em si mesma, ou seja, não se vislumbra a presença da histórica associação entre capital e trabalho. Já em uma relação de trabalho a citada prestação é utilizada como instrumento para prestar/alcançar um outro serviço, ocorrendo uma inserção no processo produtivo do empregador, agregando-lhe algum valor a sua atividade econômica.

A dilatação dos limites materiais da competência da Justiça do trabalho encontra sua barreira intransponível na relação de consumo, sob pena de, se desobedecida, resultar em um conflito de competências perante a Justiça Ordinária.

Portanto, defende-se aqui o incontestável fato de que a Justiça do Trabalho teve sua competência ampliada pela Reforma do Judiciário (Emenda Constitucional n ${ }^{\circ} 45$ ), abrangendo agora toda forma de relação de trabalho e suas ações conexas. Porém, as relações de consumo ainda fogem, felizmente, dessa nova competência material.

Não se deve negar a assertiva de que a evolução do direito ocorre com a sua aplicação no mundo concreto, com a sua vivência e utilização por aqueles que dele necessitam, de tal sorte que a visão defendida nesse estudo não deve ser confundida com uma verdade imutável defendida pelos autores, e, sim, como mais uma contribuição à doutrina que continua à procura dessa polêmica questão, trazendo um dos possíveis pontos de vista para a questão de serem ou não de competência da Justiça do Trabalho a análise sobre as relações de consumo.

\section{REFERÊNCIAS}

BRASIL. Constituição (1988). Constituição da República Federativa do Brasil. Brasília, DF, Senado, 1988.

. CDG (1990). Código de Defesa do Consumidor. Lei nº 8.078, Brasília, DF, Senado, 1988. . CG (2002). Código Civil. Brasília, DF, Senado, 2002.

. Emenda Constitucional no. 45, de 31 de dezembro de 2004. Brasília, DF, Senado, 2004. 
TST (2009). INCOMPETÊNCIA DA JUSTIÇA DO TRABALHO. COBRANÇA DE HONORÁRIOS PROFISSIONAIS. CONTRATO DE PRESTAÇÃO DE SERVIÇOS. Tribunal Superir do Trabalho. RR-1.110/2007-07502-00, Ac. $1^{a}$ Turma, Rel. Min. Lélio Bentes Corrêa, DJ 5/6/2009.

. TST (2009). AGR AVO DE INST RUMENTO. AÇÃO DE COBRANÇA DE HONORÁRIOS ADVOCATÍCIOS. INCOMPETÊNCIA DA JUSTIÇA DO TRABALHO. Tribunal Superior do Trabalho.AIRR-67/2007-381-04-40, Ac. $2^{\text {a }}$ Turma, Rel. Min. José Simpliciano Fontes de F. Fernandes, DJ 31/07/2009.

STJ. Súmula no 363: "Compete à Justiça estadual processar e julgar a ação de cobrança ajuizada por profissional liberal contra cliente. Superior Tribunal de Justiça. Publicada em: 15.10.2008, DJ: 03.11.2008.

GIGLIO, Wagner D.; CORRÊA, Claudia Giglio Veltri. Direito Processual do Trabalho. 15. ed. São Paulo: Saraiva, 2005.

MARTINS, Sergio Pinto. Direito Processual do Trabalho. 25. ed. São Paulo: Atlas, 2006.

Revista IOB Trabalhista e Previdenciária. N. 213, São Paulo: Thomson, 2007.

NASGIMENTO, Amauri Mascaro. Curso de Direito Processual do Trabalho. 21. ed. São Paulo: Saraiva, 2002.

PAMPLONA FILHO, Rodolfo. A Nova Competência da Justiça do Trabalho. Revista LTr. V. 70. N.1. São Paulo, jan/2006.

PEDUZZI, Maria Cristina Irigoyen. Revista Trabalho e Ambiente v.4, n.6, JAN/JUN, 2006.

PINTO, José Augusto Rodrigues. Processo Trabalhista de Conhecimento. 7. ed. São Paulo: LTr, 2005.

SCHIAVI, Mauro. Manual de Direito Processual do Trabalho. 2. ed. São Paulo: LTr, 2009. 


\section{CONSUMER AND LABOR RELATIONSACCORDING TO BRAZILIAN LABOR COURTS}

Abstract: The present paper shows which justice holds the competence to analyze labor and consumption relations, bringing ways to realize the difference between them. To achieve this, we bring the concept of such relations, analyzing the labor justice competence after the constitutional amendment $\mathrm{n}^{\circ} 45$, which still brings controversial issues. It analyzes the conflict of competence among the justice responsible to approach the civil relations involving services, introducing the current understanding of the Superior Court about this question and the different points of views among scholars.

Keywords: Competence. Labor and consumption relations. Constitutional amendment $n^{\circ} 45$. 